Physica B 165\&166 (1990) 1385-1386

North-Holland

\title{
THE INFLUENCE OF ADDITIVES ON THE CURRENT CARRYING CAPACITY OF BULK YBa $\mathrm{Cu}_{3} \mathrm{O}_{\mathrm{x}}$
}

\author{
A.R. Kuper *, P. Hoogendam ${ }^{+}$, H. Hemmes *, B.H. Kolster ${ }^{+}$and L.J.M. van de Klundert * \\ * University of Twente, Applied Physics, P.O.Box 217, NL-7500 AE Enschede, the Netherlands \\ + Foundation for Advanced Metals Science, P. O. Box 8039, NL-7550 KA Hengelo, the Netherlands
}

\begin{abstract}
We studied the influence of using different powders and several additives on the shaping process and critical current density of sintered bulk $\mathrm{YBa}_{2} \mathrm{Cu}_{3} \mathrm{O}_{\mathrm{x}}$. It was found that all additives used facilitated the shaping process. Silver and most organic additives influenced the critical current density only little, Zinc reduced it to zero, but an ethylenebisstearoylamide compound doubled the critical current density as compared to samples without additives.
\end{abstract}

\section{INTRODUCTION}

For sintered bulk $\mathrm{YBa}_{2} \mathrm{Cu}_{3} \mathrm{O}_{\mathrm{x}}$ the critical current density typically is a few $\mathrm{A} / \mathrm{mm}^{2}$. For applications, this will have to be at least one order of magnitude larger. This has been achieved by, for instance, melt processing $(1,2)$. This technique, however, only improves the current carrying capacity on a small length scale. The alm of our work was to improve the current carrying capacity of bulk $\mathrm{YBa}_{2} \mathrm{Cu}_{3} \mathrm{O}_{x}$ by using additives.

\section{EXPERIMENTAL}

For the determination of the critical current we used an inductive technique. By applying an $\mathrm{AC}$ field a current is induced in a ring shaped $\mathrm{YBa}_{2} \mathrm{Cu}_{3} \mathrm{O}_{\mathrm{x}}$ sample. The induced current can be measured using pickup coils (3). This technique has the advantage that a large current can be generated (presently up to $10 \mathrm{kA}$ ) without having to make contacts to the sample. The main disadvantage is that the sample has to be ring shaped. The rings are made by uniaxially compressing $\mathrm{YBa}_{2} \mathrm{Cu}_{3} \mathrm{O}_{x}$ powder in a mold, followed by cold isostatic pressing. The rings typically have an inner (outer) diameter of $25(29) \mathrm{mm}$ and a thickness of $2 \mathrm{~mm}$. The current carrying cross section is therefore $4 \mathrm{~mm}^{2}$.

The mechanical and superconductive properties of the resulting rings depend strongly on the shape and size of the powder used. We have used powders prepared by the standard solid state reaction method (standard powder), with a grain size of the order of a hundred $\mu \mathrm{m}$. We also used powders prepared by the citrate synthesis and pyrolysis method (citrate powder) (4) with a typical grain size of less than $10 \mu \mathrm{m}$ and an irregular shape.

It was found that it is difficult to form a mechanically stable ring using the citrate powder because it is very fine. This problem can be solved by mixing the $\mathrm{YBa}_{2} \mathrm{Cu}_{3} \mathrm{O}_{x}$ powder with another powder that acts as a binder. For this purpose we have used Zinc, Silver and several orga- nic compounds. As a reference we also prepared rings without any additives. All rings received the same heat treatment in 1 bar of flowing oxygen: 5 hours at $500{ }^{\circ} \mathrm{C}$ to remove the binder, 10 hours at $925^{\circ} \mathrm{C}$ for sintering and finally 10 hours at $400{ }^{\circ} \mathrm{C}$ to restore the oxygen contents.

\section{RESULTS}

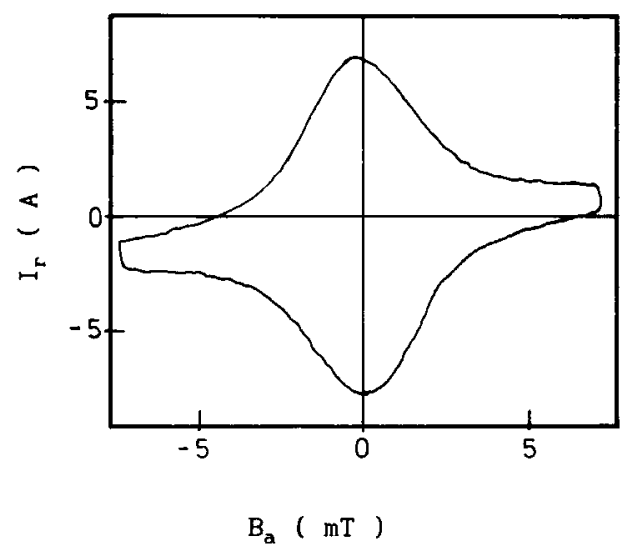

FIGURE 1. Hysterisis curve of the induced current against the applied magnetic induction for a ring prepared from citrate powder without additives.

Rings made from citrate powder without any additives have a critical current density of $\sim 2$ $\mathrm{A} / \mathrm{mm}^{2}$. A typical hysterisis curve of the generated current as a function of the applied magnetic field, measured at $77 \mathrm{~K}$, is shown in figure 1 . The curve contains a small contribution proportional to the applied field because of an imperfect compensation of the pick up coils. The critical current determined from this curve is 7 A, corresponding to a current density of 1.75 $\mathrm{A} / \mathrm{mm}^{2}$. 
Figure 2 shows the induced current in the sample with Zinc added, measured at $77 \mathrm{~K}$. The shape of the curve is completely different from that in $\mathrm{fig}$. 1. Also, because of the small signal, the imperfect compensation of the pick up coils has a much larger influence. We conclude

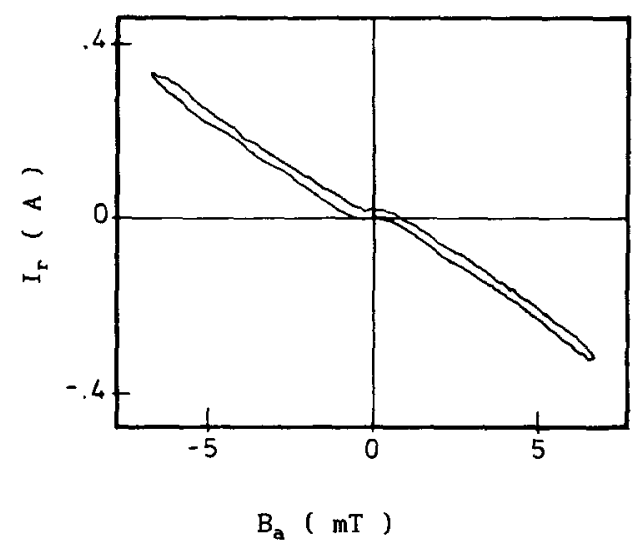

FIGURE 2. Hysterisis curve of the induced current against the applied magnetic induction for a ring prepared from citrate powder with Zinc added.

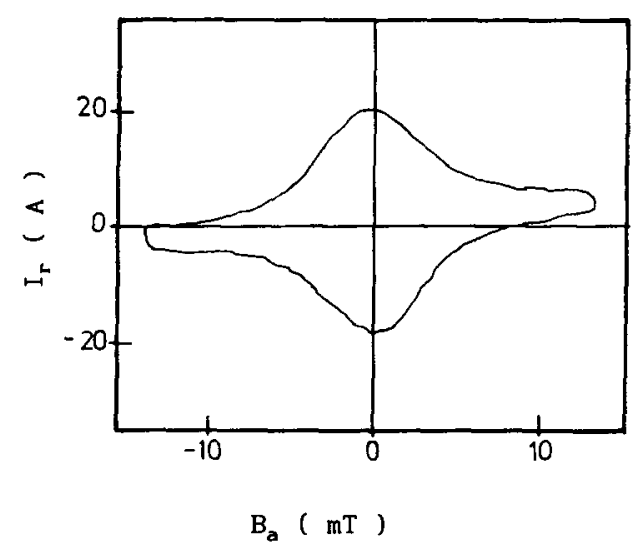

FIGURE 3. Hysterisis curve of the induced current against the applied magnetic induction for a ring prepared from citrate powder with ethylenebisstearoylamide added. from this figure that the sample is not superconducting and has therefore a zero critical current.

Figure 3 shows the hysteris curve of a sample with ethylenebisstearoylamide added. The curve has the same form as in $\mathrm{fig} .1$, but the current is much larger: $20 \mathrm{~A}$, corresponding to a current density of $5 \mathrm{~A} / \mathrm{mm}^{2}$. The largest critical current density obtained with this additive is $10 \mathrm{~A} / \mathrm{mm}^{2}$.

\section{DISCUSSION}

Zn has a very high vapor pressure and was thought to evaporate before the sinter process started. It showed however that $\mathrm{Zn}$ reacts with oxygen, released from the $\mathrm{Cu}-\mathrm{O}$ planes, forming $\mathrm{ZnO}$. As a result the critical current density was reduced to zero. All organic binders decomposed before the sinter process started and did not influence the critical current density. However, for the ethylenebisstearoylamide compound the critical current density doubled as compared to the reference samples. Finally, adding Silver to the $\mathrm{YBa}_{2} \mathrm{Cu}_{3} \mathrm{O}_{\mathrm{x}}$ powder has little influence on the critical current.

\section{CONCLUSIONS}

We have found that ring made from citrate powder have a larger critical current density than those made from standard powder. Furthermore, additives have shown to be very helpfull in the shaping process and do not necessarily have a negative effect on the critical current density in bulk $\mathrm{YBa}_{2} \mathrm{Cu}_{3} \mathrm{O}_{\mathrm{x}}$. Adding ethylenebisstearoylamide doubled the critical current density.

\section{ACKNOWLEDGEMENTS}

We would like to acknowlegde the National Research Program for High Temperature Superconductors (NOP-HTC) for their financial support.

\section{REFERENCES}

(1) S. Jin, T.H. Tiefel, R.C. Sherwood, M.E. Davis, R.B. van Dover, G.W. Kammlott, R.A. Fastnacht, and H.D. Keith, Appl. Phys. Lett. 52 (1988) 2074

(2) K. Salama, V. Selvamancickam, L. Gao and K. Sun, Appl Phys. Lett. 54 (1989) 2352

(3) L.J.M. van de Klundert, P. Out, B. ten Haken, G.J.M. Velders, D.H.A. Blank and W.S.J. Uijttewaal, in: Proceedings of the European Workshop on HIGH $T_{c}$ SUPERCONDUCTORS AND POTENTIAL APPLICATIONS, 1-3 July, 1987

(4) D.H.A. Blank, H. Kruidhof and J. Flokstra, J. Phys. D: Appl. Phys. 21 (1988) 226 